\title{
Two adjacent C-terminal mutations enable expression of aryl-alcohol oxidase from Pleurotus eryngii in Pichia pastoris
}

\author{
Nina Jankowski ${ }^{1} \cdot$ Vlada B. Urlacher $^{1} \cdot$ Katja Koschorreck $^{1}$ (1)
}

Received: 9 July 2021 / Revised: 23 August 2021 / Accepted: 26 August 2021 / Published online: 21 September 2021

(c) The Author(s) 2021, corrected publication 2022

\begin{abstract}
Fungal aryl-alcohol oxidases (AAOs) are attractive biocatalysts because they selectively oxidize a broad range of aromatic and aliphatic allylic primary alcohols while yielding hydrogen peroxide as the only by-product. However, their use is hampered by challenging and often unsuccessful heterologous expression. Production of PeAAO1 from Pleurotus eryngii ATCC 90787 in Pichia pastoris failed, while PeAAO2 from P. eryngii $\mathrm{P} 34$ with an amino acid identity of $99 \%$ was expressed at high yields. By successively introducing mutations in PeAAO1 to mimic the sequence of $P e A A O 2$, the double mutant $P e A A O 1$ ER with mutations K583E and Q584R was constructed, that was successfully expressed in P. pastoris. Functional expression was enhanced up to $155 \mathrm{U} / \mathrm{l}$ via further replacements D361N (variant NER) or V367A (variant AER). Fed-batch cultivation of recombinant $P$. pastoris yielded up to $116 \mathrm{mg} / \mathrm{l}$ of active variants. Glycosylated $P e$ AAO1 variants demonstrated high stability and catalytic efficiencies similar to PeAAO2. Interestingly, P. pastoris expressing PeAAO1 variant ER contained roughly 13 gene copies but showed similar volumetric activity as NER and AER with one to two gene copies and four times lower mRNA levels. Additional H-bonds and salt bridges introduced by mutations K583E and Q584R might facilitate heterologous expression by enhanced protein folding.
\end{abstract}

Key points

- PeAAO1 not expressed in P. pastoris and PeAAO2 well-expressed in Pichia differ at 7 positions.

- Expression of PeAAO1 in P. pastoris achieved through mutagenesis based on PeAAO2 sequence.

- Combination of K583E and Q584R is essential for expression of PeAAO1 in P. pastoris.

Keywords Pichia pastoris (Komagataella phaffi) $\cdot$ Aryl-alcohol oxidase $\cdot$ Pleurotus eryngii $\cdot$ Site-directed mutagenesis . Salt bridges $\cdot$ Gene copy number

\section{Introduction}

Flavin-dependent oxidases build a diverse group of enzymes that have been successfully used in biocatalysis and biosensors (Dijkman et al. 2013). An important prerequisite for the application of these enzymes is their availability at high quantities. In this regard, heterologous expression in microbial hosts has been recognized as the most efficient approach which on the one hand, opens the way to high-scale processes and, on the other hand, when combined with protein engineering enables production and

Katja Koschorreck

Katja.Koschorreck@hhu.de

1 Institute of Biochemistry, Heinrich-Heine-University Düsseldorf, Universitätsstraße 1, 40225 Düsseldorf, Germany screening of mutants or mutant libraries to "tailor" the optimal biocatalyst for a specific purpose ( $\mathrm{Li}$ and Cirino 2014). Aryl-alcohol oxidases (AAOs, EC 1.1.3.7) belong to flavin-dependent oxidases (Serrano et al. 2020). They contain a non-covalently bound FAD and catalyze the oxidation of primary aromatic and aliphatic allylic alcohols to the corresponding aldehydes, and if the gem-diol is formed, also to the corresponding acids (Ferreira et al. 2010; Guillén et al. 1992). AAOs are predominantly produced in wood-decaying fungi and secreted as glycoproteins. For their reactions, AAOs require only molecular oxygen and release hydrogen peroxide as the by-product (Guillén et al. 1992). Various studies have demonstrated the potential of AAOs for biotechnology (Urlacher and Koschorreck 2021). The most studied representative of this group is the AAO from Pleurotus eryngii ATCC 90787 (further designated as PeAAO1), that among others 
was applied for the production of the flavor and fragrance compound trans-2-hexenal (de Almeida et al. 2019; van Schie et al. 2018). This enzyme was also used for the conversion of 5-hydroxymethylfurfural to 2,5-furandicarboxylic acid as precursor for bioplastics in multi-enzyme cascades (Carro et al. 2014; Serrano et al. 2019a). Furthermore, $P e \mathrm{AAO} 1$ was engineered to oxidize secondary alcohols to facilitate kinetic deracemization (Serrano et al. 2019b; Viña-Gonzalez et al. 2019). PeAAO1 has served as a model enzyme for numerous investigations providing insights into substrate spectrum, structural, and mechanistic properties of AAOs (Carro et al. 2017, 2018; Fernández et al. 2009; Ferreira et al. 2009, 2010; Guillén et al. 1992; Hernández-Ortega et al. 2012a, 2012b). However, heterologous expression of PeAAO1 and AAOs in general is quite challenging and often unsuccessful or leads to only low amounts of active enzyme (Urlacher and Koschorreck 2021). For example, heterologous expression of PeAAO1 in Aspergillus nidulans yielded $3 \mathrm{mg} / \mathrm{l}$ of active enzyme, while expression in Escherichia coli led to the formation of inclusion bodies and required time-consuming refolding of $P e \mathrm{AAO} 1$ which was less stable than the native enzyme due to the lack of glycosylation (Ferreira et al. 2005; RuizDueñas et al. 2006). Aiming at enhanced expression in Saccharomyces cerevisiae and Pichia pastoris, PeAAO1 was subjected to protein engineering using in vivo DNA shuffling and the mutagenic organized recombination process by homologous in vivo grouping (MORPHING) (Viña-Gonzalez et al. 2015, 2018). As result, two PeAAO1 variants, FX7 and FX9, were constructed and expressed at concentrations of up to $25 \mathrm{mg} / \mathrm{l}$. A recent review summarized different approaches of directed evolution to unlock PeAAO1's full potential for biotechnological purposes aiming at enhanced expression or acceptance of new substrates (Viña-Gonzalez and Alcalde 2020).

Recently, we cloned an aryl-alcohol oxidase PeAAO2 from $P$. eryngii $\mathrm{P} 34$ in $P$. pastoris and produced it in a fedbatch process at a concentration of $315 \mathrm{mg} / \mathrm{l}$ (Jankowski et al. 2020). Interestingly, the protein sequences of $P e \mathrm{AAO} 2$ and PeAAO1 differ only in seven amino acid residues. Our efforts to actively express $P e$ AAO 1 in $P$. pastoris failed and an explanation why the highly similar $\mathrm{PeAAO} 2$ was expressed at high yields remained elusive. Here, we investigate the effect of the seven different amino acid residues on expression of PeAAO1 in P. pastoris. A set of single, double and triple mutants of $P e A A O 1$ were generated and their expression levels were examined. The most active variants were produced in a fed-batch process, purified, and characterized. Homology models of the active variants were created in order to rationalize the effect of the mutations based on the structural changes. The gene copy numbers and mRNA levels of recombinant $P$. pastoris expressing $P e \mathrm{AAO} 1$ variants were investigated by real-time PCR to determine the effects of these parameters on enzyme expression.

\section{Materials and methods}

\section{Chemicals}

All chemicals were of analytical grade or higher and purchased from Acros Organics (Geel, Belgium), AppliChem GmbH (Darmstadt, Germany), BD (Heidelberg, Germany), Carl Roth GmbH + Co. KG (Karlsruhe, Germany), J\&K Scientific (Lommel, Belgium), and Sigma-Aldrich (Schnelldorf, Germany).

\section{Strains and plasmids}

For all cloning procedures, chemically competent Escherichia coli DH5 $\alpha$ cells were used (Clontech Laboratories Inc., Heidelberg, Germany). The expression of the PeAAO1 variants was carried out using $P$. pastoris X-33 (recently reclassified as Komagataella phaffii) cells transformed with pPICZA-based plasmids containing the methanol inducible AOX1-promoter (Invitrogen, Carlsbad, USA).

\section{Site-directed mutagenesis}

The gene peaaol encoding for P. eryngii ATCC 90787 arylalcohol oxidase 1 (GenBank accession number AF064069) was synthesized and cloned into pPICZA vector by BioCat $\mathrm{GmbH}$ (Heidelberg, Germany) in a codon optimized version (GenBank accession number MZ246833) for expression in yeast (JCat online tool) (Grote et al. 2005). The resulting plasmid pPICZA_PeAAO1 was used as template for sitedirected mutagenesis using the QuikChange protocol with the primers listed in Supplemental Table S1. First, seven single mutants, R152G, T265I, D361N, V367A, D512N, $\mathrm{K} 583 \mathrm{E}$, and Q584R, were generated according to the following procedure. One nanogram of pPICZA_PeAAO1 was mixed with $500 \mathrm{nM}$ each forward and reverse primer, $200 \mu \mathrm{M}$ of each dNTP, $1 \times$ high-fidelity buffer, $3 \%$ dimethyl sulfoxide (DMSO), and $0.02 \mathrm{U} / \mu \mathrm{l}$ Phusion High-Fidelity DNA-polymerase (Thermo Fisher Scientific, Bremen, Germany) in a total volume of $50 \mu \mathrm{l}$. Using a thermocycler, following cycling protocol was used: initial denaturation at $98^{\circ} \mathrm{C}$ for $30 \mathrm{~s}, 16$ times cycling of denaturation at $98^{\circ} \mathrm{C}$ for $10 \mathrm{~s}$, annealing for $30 \mathrm{~s}$, extension at $72{ }^{\circ} \mathrm{C}$ for $75 \mathrm{~s}$, followed by a final extension at $72{ }^{\circ} \mathrm{C}$ for $10 \mathrm{~min}$, and a hold at $10^{\circ} \mathrm{C}$. The annealing temperature for each primer pair was calculated using the $\mathrm{T}_{\mathrm{m}}$ calculator of Thermo Fisher Scientific.

To remove the parental plasmid, the reaction mixture was digested with FastDigest $D p n \mathrm{I}$ (Thermo Fisher Scientific). Chemically competent $E$. coli DH5 $\alpha$ cells were transformed 
with the digested sample and plated on selective LB agar plates ( $1 \%$ peptone, $0.5 \%$ yeast extract, $0.5 \% \mathrm{NaCl}, 1.5 \%$ agar) containing $25 \mu \mathrm{g} / \mathrm{ml}$ Zeocin ${ }^{\mathrm{TM}}$ (InvivoGen, San Diego, USA). Up to five randomly selected colonies were used to inoculate $5 \mathrm{ml}$ of LB medium with $25 \mu \mathrm{g} / \mathrm{ml} \mathrm{Zeocin}{ }^{\mathrm{TM}}$ and incubated overnight $\left(37^{\circ} \mathrm{C}, 180 \mathrm{rpm}\right)$. Plasmid isolation was carried out using the ZR Plasmid Miniprep Kit (Zymo Research, Freiburg, Germany) following the manufacturer's instructions. Introduction of mutations was verified through DNA sequencing by Eurofins Genomics Germany $\mathrm{GmbH}$ (Ebersberg, Germany). Once all seven single mutants were generated and evaluated regarding enzyme activity (see below), pPICZA_PeAAO1_K583E was used as plasmid template to generate six double mutants (R152G/K583E, T265I/K583E, D361N/K583E, V367A/K583E, D512N/ K583E, and K583E/Q584R) as described above. Finally, single mutations D361N and V367A were introduced in the double mutant K583E/Q584R (variant ER) using pPICZA_PeAAO1_K583E/Q584R as template to construct the two triple mutants D361N/K583E/Q584R (variant NER) and V367A/K583E/Q584R (variant AER), respectively.

All generated pPICZA-based plasmids were linearized in the 5' $A O X 1$ region employing the FastDigest MssI enzyme (Thermo Fisher Scientific). Electrocompetent P. pastoris $\mathrm{X}-33$ cells were transformed with the linearized plasmids, plated on YPDS agar plates (1\% yeast extract, $2 \%$ peptone, $2 \%$ dextrose, $1 \mathrm{M}$ sorbitol, $2 \%$ agar) containing $100 \mu \mathrm{g} /$ $\mathrm{ml} \mathrm{Zeocin}{ }^{\mathrm{TM}}$ and incubated at $30{ }^{\circ} \mathrm{C}$ until the formation of colonies.

\section{Enzyme production and purification}

A number of $P$. pastoris transformants expressing either the mutants K583E/Q584R (variant ER), D361N/K583E/Q584R (variant NER) or V367A/K583E/Q584R (variant AER) were cultivated in $10 \mathrm{ml}$ BMGY medium (1\% yeast extract, $2 \%$ peptone, $100 \mathrm{mM}$ potassium phosphate buffer $\mathrm{pH}$ 6, 1.34\% yeast nitrogen base without amino acids, $4 \times 10^{-5} \%$ biotin, $1 \%$ glycerol) in $100-\mathrm{ml}$ shaking flasks overnight $\left(30^{\circ} \mathrm{C}\right.$, $200 \mathrm{rpm}$ ) and used to inoculate $10 \mathrm{ml}$ of the expression medium BMMY (1\% yeast extract, $2 \%$ peptone, $100 \mathrm{mM}$ potassium phosphate buffer $\mathrm{pH} 6,1.34 \%$ yeast nitrogen base without amino acids, $4 \times 10^{-5} \%$ biotin and $0.5 \%(\mathrm{v} / \mathrm{v})$ methanol) to an $\mathrm{OD}_{600}$ of 1 . The expression was carried out for up to $48 \mathrm{~h}\left(25^{\circ} \mathrm{C}, 200 \mathrm{rpm}\right)$ and methanol was added every $24 \mathrm{~h}$ at $0.5 \%(\mathrm{v} / \mathrm{v}) . \mathrm{OD}_{600}$ value and volumetric activity were monitored daily and used to identify the best performing recombinant Pichia transformants.

Fed-batch cultivation of the selected P. pastoris transformants expressing ER, NER, and AER with glycerol as carbon source during the batch phase and $0.5 \%(\mathrm{v} / \mathrm{v})$ methanol with $12 \mathrm{~g} / 1$ Pichia trace metals $\left(\mathrm{PTM}_{1}\right)$ solution during the fed-batch phase were carried out as described previously
(Jankowski et al. 2020). Daily sampling was done to monitor cell growth, extracellular protein concentration, and volumetric activity. After 8 or 9 days of cultivation, the cells were harvested via centrifugation $\left(11,325 \times g, 15 \mathrm{~min}, 4^{\circ} \mathrm{C}\right)$. The cell-free supernatant was concentrated and rebuffered using tangential flow filtration (TFF) and subsequently purified via three chromatographic steps, as described before for PeAAO2 (Jankowski et al. 2020). In short, $5 \mathrm{ml}$ of the first eluate from TFF was applied to a hydrophobic interaction chromatography column (Butyl Sepharose HP, GE Healthcare, Freiburg, Germany) and eluted with decreasing ammonium sulfate concentration. Active fractions were pooled, desalted, and loaded onto an anion exchange chromatography column (DEAE Sepharose FF, GE Healthcare) and eluted with increasing sodium chloride concentration. Again, active fractions were pooled and finally loaded onto a size exclusion chromatography column (Superdex 200 Increase 10/300 GL, GE Healthcare). The most active and purest fractions were concentrated, desalted, and stored at $4{ }^{\circ} \mathrm{C}$ until use. The production and chromatographic purification of $\mathrm{PeAAO} 2$ were carried out as described before (Jankowski et al. 2020).

\section{Enzyme activity assay}

The standard assay to assess AAO activity in the culture supernatant or of purified enzyme was carried out with veratryl alcohol as substrate at room temperature. $5 \mathrm{mM}$ of veratryl alcohol was mixed with $100 \mathrm{mM}$ sodium phosphate buffer $\mathrm{pH} 6$, and the reaction was initiated with culture supernatant or an appropriate dilution of AAO containing sample in a 1-ml cuvette. The change of absorbance at $310 \mathrm{~nm}$ as a result of veratraldehyde formation $\left(\varepsilon_{310}=9,300 \mathrm{M}^{-1} \mathrm{~cm}^{-1}\right)$ (Guillén et al. 1992) was followed using an Ultrospec 7000 photometer (GE Healthcare). Initial reaction rates were calculated according to Lambert-Beer law. Under the stated conditions, one unit of activity is defined as the amount of enzyme that converts $1 \mu \mathrm{mol}$ substrate per minute.

\section{Protein quantification and $\mathbf{N}$-deglycosylation}

To determine protein concentrations at different steps of enzyme purification, the Bradford method was used employing bovine serum albumin as standard protein (Bradford 1976). The measurements were carried out at room temperature in 96-well micro titer plates using an Infinite M200 Pro plate reader (Tecan, Männedorf, Switzerland). The molar extinction coefficients of purified $P e A A O 1$ variants were calculated after heat denaturation of the samples and detection of released FAD as described for PeAAO2 wild-type (Jankowski et al. 2020) and used for determination of molar enzyme concentrations. Latter ones were used to calculate enzyme concentration in 
fermentation supernatant, specific activities of purified enzymes, and kinetic constants.

$N$-Deglycosylation was performed using $20 \mu \mathrm{g}$ of purified enzymes and peptide- $N$-amidase PNGase F (New England Biolabs, Frankfurt am Main, Germany) under denaturing conditions. For this, the samples were boiled at $100{ }^{\circ} \mathrm{C}$ for $10 \mathrm{~min}$ in the presence of SDS prior to deglycosylation with PNGase F. An aliquot of the deglycosylated samples as well as of the purified enzymes (each $5 \mu \mathrm{g}$ ) were loaded onto a $12.5 \%$ resolving gel and SDS-PAGE was conducted according to the protocol of Laemmli (1970).

\section{pH activity, stability, and melting temperature}

The activity of $P e \mathrm{AAO} 1$ variants ER, NER, and AER and $P e A A O 2$ wild-type towards the substrates $p$-anisyl alcohol and veratryl alcohol was determined in $100 \mathrm{mM}$ BrittonRobinson buffer (consisting of $100 \mathrm{mM}$ each boric acid, phosphoric acid, acetic acid) at different $\mathrm{pH}$ values ranging from $\mathrm{pH} 2$ to 10 at room temperature. To determine the $\mathrm{pH}$ stability, the enzymes were incubated for up to $24 \mathrm{~h}$ in $100 \mathrm{mM}$ Britton-Robinson buffer at $\mathrm{pH} 2$ to 10 at room temperature. After certain time points, samples were taken and the relative activity towards veratryl alcohol was determined as described in the standard assay.

The melting temperature $\left(T_{\mathrm{M}}\right)$ of the PeAAO1 variants ER, NER, and AER was determined by the ThermoFAD assay (Forneris et al. 2009). The temperature at which 50\% of the enzymatic activity is retained $\left(T_{50}\right)$ was determined for the PeAAO1 variants as previously described (Jankowski et al. 2020).

\section{Specific activities}

The activity of purified PeAAO1 variants ER, NER, and AER as well as of $P e A A O 2$ was determined towards several AAO substrates at a final concentration of $5 \mathrm{mM}$ in $100 \mathrm{mM}$ sodium phosphate buffer $\mathrm{pH} 6$ at room temperature. The assay was performed in 96-well UV-Star ${ }^{\circledR}$ micro titer plates (Greiner Bio-One GmbH, Frickenhausen, Germany). The conversion of the selected alcohols to their corresponding aldehydes was followed spectrophotometrically using the Infinite M200 Pro plate reader (Tecan): $p$ - anisyl alcohol $\left(\varepsilon_{285}=16,980 \mathrm{M}^{-1} \mathrm{~cm}^{-1}\right) \quad($ Guillén et al. 1992), benzyl alcohol $\left(\varepsilon_{250}=13,800 \mathrm{M}^{-1} \mathrm{~cm}^{-1}\right)$ ( Guillén e t a l. 1992 ), piperonyl alcohol $\left(\varepsilon_{317}=8,680 \mathrm{M}^{-1} \mathrm{~cm}^{-1}\right) \quad(\mathrm{J}$ ankowski et al. 2020), veratryl alcohol $\left(\varepsilon_{310}=9,300 \mathrm{M}^{-1} \mathrm{~cm}^{-1}\right)$ (Guillén et al. 1992), and trans,trans-2,4-hexadienol $\left(\varepsilon_{280}=30,140 \mathrm{M}^{-1} \mathrm{~cm}^{-1}\right)$ (Ruiz-Dueñas et al. 2006).

\section{Determination of kinetic parameters}

The kinetic parameters of the oxidation of $p$-anisyl alcohol $(0.98$ to $1,000 \mu \mathrm{M})$ and veratryl alcohol $(9.8$ to $10,000 \mu \mathrm{M})$ with the purified $P e A A O 1$ variants ER, NER, and AER were determined in 96-well UV-Star ${ }^{\circledR}$ micro titer plates at $25^{\circ} \mathrm{C}$ using an Infinite M200 Pro plate reader (Tecan). An appropriate stock solution of purified enzyme was mixed with $100 \mathrm{mM}$ sodium phosphate buffer $\mathrm{pH} 6$ and substrate stocks with varying concentrations. Using the program OriginPro 2019 (OriginLab Corporation, Northampton, MA, USA), a non-linear fit according to the Michaelis-Menten equation was calculated and the parameters $\mathrm{V}_{\max }$ and $\mathrm{K}_{\mathrm{M}}$ were extracted and used for calculation of $\mathrm{k}_{\mathrm{cat}}$ and $\mathrm{k}_{\mathrm{cat}} / \mathrm{K}_{\mathrm{M}}$ values.

\section{Real-time PCR to determine gene copy numbers and mRNA levels}

For extraction of genomic DNA (gDNA) in order to determine the gene copy numbers, precultures of recombinant $P$. pastoris transformants expressing different $P e A A O 1$ variants were cultivated in $10 \mathrm{ml} \mathrm{BMGY}$ medium overnight $\left(30^{\circ} \mathrm{C}\right.$, $200 \mathrm{rpm})$. The gDNA was extracted using the Quick-DNA Fungal/Bacterial Miniprep Kit (Zymo Research, Freiburg, Germany) according to the manufacturer's protocol and eluted in $50 \mu \mathrm{l}$ of ultra-pure water. The precultures were used to inoculate $10 \mathrm{ml}$ of BMM medium $(100 \mathrm{mM}$ potassium phosphate buffer $\mathrm{pH} 6,1.34 \%$ yeast nitrogen base without amino acids, $4 \times 10^{-5} \%$ biotin, and $0.5 \%(\mathrm{v} / \mathrm{v})$ methanol) to an $\mathrm{OD}_{600}$ of 1 , and cultures were incubated for $48 \mathrm{~h}\left(25^{\circ} \mathrm{C}\right.$, $200 \mathrm{rpm})$. Samples diluted to an $\mathrm{OD}_{600}$ of 1 were used for total RNA extraction using the RNeasy Mini Kit (Qiagen, Hilden, Germany) according to the manufacturer's protocol. On-column digestion of residual DNA with RNase-free DNase set (Qiagen) during purification was implemented. gDNA and RNA concentrations were measured spectrophotometrically using the NanoQuant ${ }^{\mathrm{TM}}$ Plate with the Infinite M200 Pro plate reader (Tecan) by determining the $260 \mathrm{~nm}$ absorbance and 260/280 nm ratio. One hundred nanograms of total RNA was used for cDNA synthesis using SuperScript $^{\mathrm{TM}}$ III Reverse Transcriptase (Invitrogen) with $2.5 \mu \mathrm{M}$ Oligo(dT) ${ }_{18}$ primers (Thermo Fisher Scientific) as described in the manufacturer's protocol. The resulting cDNA was diluted 1:4 with ultra-pure water.

Real-time-PCR reactions were set up with innuMIX qPCR DSGreen Standard Mix (AnalytikJena, Jena, Germany) according to the manufacturer's protocol and conducted on real-time PCR cycler qTOWER $^{3}$ touch (AnalytikJena). Either $2 \mathrm{ng}$ of gDNA or $2 \mu \mathrm{l}$ of diluted cDNA sample was used in triplicate. The cycling protocol was as followed: initial denaturation at $95^{\circ} \mathrm{C}$ for $120 \mathrm{~s}$, followed by 40 cycles of denaturation at $95^{\circ} \mathrm{C}$ for $30 \mathrm{~s}$, and combined annealing and detection at $60^{\circ} \mathrm{C}$ for $45 \mathrm{~s}$. A melting curve 
Fig. 1 Volumetric activities [U/l] of PeAAO2 wild-type and $P e \mathrm{AAO} 1$ variants in the supernatant of small-scale expressions of recombinant $P$. pastoris towards veratryl alcohol $(5 \mathrm{mM})$. Empty vector pPICZ $\alpha \mathrm{A}(\mathrm{EV})$ was used as negative control. Activities were measured after $48 \mathrm{~h}$ of cultivation in BMMY medium $\left(25^{\circ} \mathrm{C}\right.$ and $200 \mathrm{rpm}$ ) with $0.5 \%(\mathrm{v} / \mathrm{v})$ methanol added daily

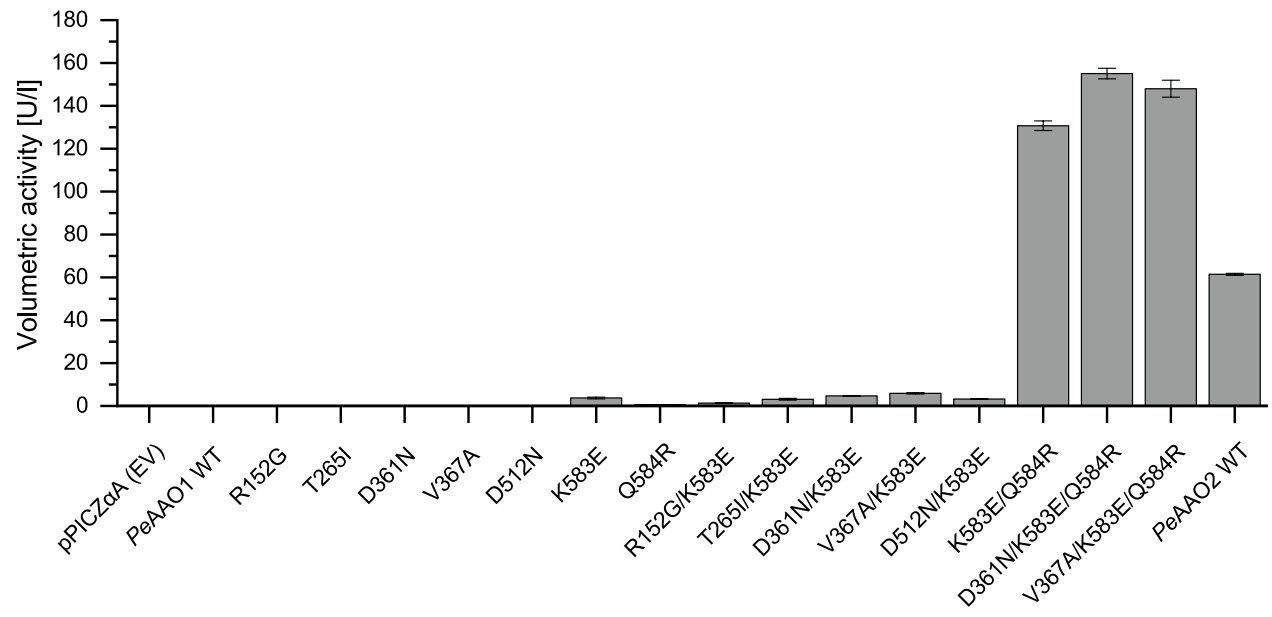

analysis was included after the PCR run from 60 to $95^{\circ} \mathrm{C}$ in $0.5{ }^{\circ} \mathrm{C}$ increments.

For amplification of target peaao genes, specific primers 1qPCR_fw (5' -3': TCCAGTTGCTAGAGGTGACATC) and 1qPCR_rev (5' -3': TGGGTCGAATGGTCTGATAACG) were used, while actin was used as reference gene with primers Actin_fw (5' -3': GGTATTGCTGAGCGTATGCAAA) and Actin_rev (5'-3': CCACCGATCCATACGGAGTACT). Optimal primer concentrations were determined by titrating forward and reverse primers at 100 to $300 \mathrm{nM}$ each, and combinations yielding no amplification in the no-template control were used. Primer efficiencies for both pairs at optimal concentrations were calculated using dilution series of gDNA. The results of gene copy number and mRNA level determination were analyzed using the software qPCRsoft 4.1 (AnalytikJena) employing the primer efficiency corrected Pfaffl method and actin as reference gene (Pfaffl 2001).

\section{Homology modelling}

The crystal structure of PeAAO1 wild-type (PDB entry 3FIM) (Fernández et al. 2009) was used as template to generate homology models of PeAAO1 variants ER, NER, and AER using the online tool SWISS-MODELL (Waterhouse et al. 2018) and the program PyMOL for visualization.

\section{Results}

\section{Effect of mutations on PeAAO1 expression}

To study the effect of the seven amino acid residues which differ in the highly expressed PeAAO2 and PeAAO1, not expressed in $P$. pastoris, at first, seven single mutants of PeAAO1 with the substitutions R152G, T265I, D361N, V367A, D512N, K583E, and Q584R were created. The corresponding $P$. pastoris transformants were screened for AAO activity after expression in BMMY medium in shaking flasks. Both AAOs, PeAAO1, and PeAAO2 have been reported to catalyze the oxidation of veratryl alcohol to veratraldehyde (Guillén et al. 1992; Jankowski et al. 2020). Thus, conversion of veratryl alcohol by samples taken from the supernatant after expression and cell centrifugation was used for expression verification. Out of the seven single mutants, activity was only detectable for the K583E variant and reached 3.7 U/1 (Fig. 1).

Despite the low volumetric activity of PeAAO1 variant K583E compared to $P e A A O 2$ wild-type with $61 \mathrm{U} / 1$, the successful expression of this variant in $P$. pastoris was a good starting point for further mutagenesis. In the next step, six PeAAO1 double mutants were created by introducing mutations R152G, T265I, D361N, V367A, D512N, and Q584R, respectively, into the $P e A A O 1$ variant K583E and screened for improved volumetric activity towards veratryl alcohol. Remarkably, the double mutant K583E/Q584R reached a volumetric activity of up to $131 \mathrm{U} / \mathrm{l}$ (Fig. 1), which is roughly 35 times higher than that of the variant K583E and even surpasses the volumetric activity of $\mathrm{PeAAO} 2$ wildtype by factor 2 . The double mutants D361N/K583E and 
V367A/K583E showed slightly increased activities (up to 4.7 U/1 and 5.9 U/l, respectively) compared to the starting variant K583E (3.7 U/l), indicating a beneficial effect of the mutations D361N and V367A on expression and/or enzyme activity. Mutations D361N and V367A, respectively, were introduced into the best double mutant K583E/Q584R yielding two triple mutants. An alignment of $P e \mathrm{AAO} 1$ and $P e \mathrm{AAO} 2$ wild-type and of $P e \mathrm{AAO} 1$ variants is given in Supplemental Fig. S1. After expression in P. pastoris, a volumetric activity of up to $155 \mathrm{U} / \mathrm{l}$ for the variant $P e \mathrm{AAO} 1$ D361N/K583E/Q584R was achieved (Fig. 1), which is 1.2fold higher than the parental double mutant K583E/Q584R and 2.5-fold higher than $P e A A O 2$ wild-type. The PeAAO1 mutant V367A/K583E/Q584R was expressed in P. pastoris leading to a similar volumetric activity of $148 \mathrm{U} / \mathrm{l}$. The PeAAO1 variants K583E/Q584R (ER), D361N/K583E/
Q584R (NER), and V367A/K583E/Q584R (AER) were selected for production at a larger scale and characterization.

\section{Production in a bioreactor and purification of active PeAA01 variants}

The fed-batch cultivation of recombinant $P$. pastoris to produce $P e$ AAO1 variants ER, NER, and AER was conducted for 8 to 9 days. $P e A A O 1$ variant ER was produced at a volumetric activity of $4898 \mathrm{U} / \mathrm{l}$ after $160 \mathrm{~h}$ (Table 1). At around the same time, NER reached $5263 \mathrm{U} / 1$ and AER yielded 5734 U/l. All enzymes were purified to homogeneity following the established three-step purification protocol (see the experimental section). Purified PeAAO1 NER exhibited the highest specific activity towards veratryl alcohol with $48.4 \mathrm{U} / \mathrm{mg}$, followed by AER with $45.6 \mathrm{U} / \mathrm{mg}$. PeAAO1 ER showed a slightly lower specific activity with $42.4 \mathrm{U} / \mathrm{mg}$
Table 1 Activity and enzyme production during fed-batch cultivation and properties of the purified $P e \mathrm{AAO} 1$ variants and $P e A A O 2$ wild-type
Fig. 2 SDS-PAGE analysis of purified and $\mathrm{N}$-deglycosylated $P e A A O 2$ wild-type and $P e \mathrm{AAO} 1$ variants. M, PageRuler ${ }^{\mathrm{TM}}$ marker; 1 , native PeAAO2; 2, deglycosylated $P e \mathrm{AAO} 2 ; 3$, native $P e \mathrm{AAO} 1$ ER; 4, deglycosylated PeAAO1 ER; 5, native $P e A A O 1$ NER; 6 , deglycosylated PeAAO1 NER; 7, native $P e$ AAO1 AER; 8 , deglycosylated $P e$ AAO1 AER. Arrow indicates PNGase $\mathrm{F}$ $(36 \mathrm{kDa}) .5 \mu \mathrm{g}$ of each sample was loaded and the gel was stained with Coomassie Brilliant Blue R250

\begin{tabular}{lllll}
\hline Enzyme & PeAAO1 ER & PeAAO1 NER & PeAAO1 AER & PeAAO2 WT \\
\hline${\text { Volumetric activity after } \sim 160 \mathrm{~h}[\mathrm{U} / \mathrm{l}]^{\mathrm{a}}}^{\mathrm{a}}$ & $4898(160 \mathrm{~h})$ & $5263(159 \mathrm{~h})$ & $5734(160 \mathrm{~h})$ & $5229(167 \mathrm{~h})$ \\
${\text { Enzyme concentration }[\mathrm{mg} / \mathrm{l}]^{\mathrm{b}}}$ & $116(160 \mathrm{~h})$ & $113(183 \mathrm{~h})$ & $98(179 \mathrm{~h})$ & $169(214 \mathrm{~h})$ \\
${\text { Specific activity }[\mathrm{U} / \mathrm{mg}]^{\mathrm{c}}}^{\text {Absorbance maxima }[\mathrm{nm}]}$ & 42.4 & 48.4 & 45.6 & 43.0 \\
$\varepsilon_{463}$ extinction coefficient $\left[\mathrm{M}^{-1} \mathrm{~cm}^{-1}\right]$ & 463,383 & 463,383 & 463,383 & $463,376^{\mathrm{d}}$ \\
\hline
\end{tabular}

${ }^{\mathrm{a}}$ For comparison, volumetric activities after roughly $160 \mathrm{~h}$ (time of harvest for PeAAO1 ER) are shown. Enzymatic activity was determined with $5 \mathrm{mM}$ veratryl alcohol in $100 \mathrm{mM}$ sodium phosphate buffer $\mathrm{pH} 6$

${ }^{b}$ Enzyme concentration calculated based on molar protein concentration of purified enzyme. Time of harvest is given in parenthesis

${ }^{\mathrm{c}}$ Specific activity of purified enzyme towards veratryl alcohol based on molar protein concentrations

${ }^{\mathrm{d}}$ Values from (Jankowski et al. 2020)

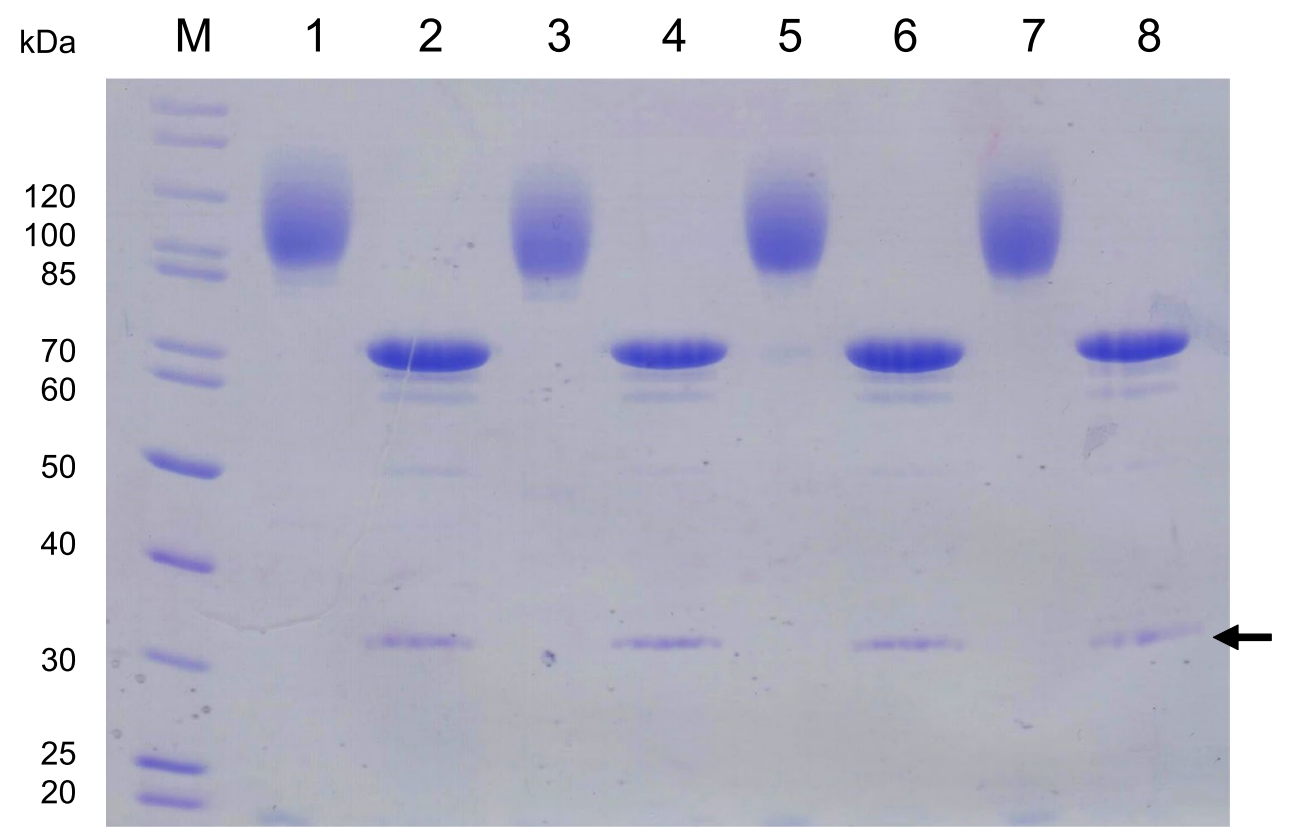


similar to PeAAO2 wild-type with $43 \mathrm{U} / \mathrm{mg}$. Molar protein concentrations calculated after purification revealed that the $P e$ AAO1 variant ER was produced at a level of $116 \mathrm{mg} / \mathrm{l}$, followed by $113 \mathrm{mg} / \mathrm{l}$ for NER and $98 \mathrm{mg} / \mathrm{l}$ for AER.

To elucidate the reasons for different expression yields of the PeAAO1 variants, their properties were investigated. All PeAAO1 mutants exhibited absorption spectra typical for flavoproteins with two absorbance maxima at $463 \mathrm{~nm}$ and $383 \mathrm{~nm}$. The molar extinction coefficients were calculated based on absorbance of the released FAD after heat precipitation of the apoprotein and ranged between 8400 and $8700 \mathrm{M}^{-1} \mathrm{~cm}^{-1}$ (Table 1).

Purified $P e \mathrm{AAO} 2$ wild-type and $P e \mathrm{AAO} 1$ variants exhibited similar apparent molecular masses of around $100 \mathrm{kDa}$ according to SDS-PAGE (lanes 1, 3, 5, and 7 in Fig. 2), while the theoretical molecular weight (without the predicted signal peptide) was $61 \mathrm{kDa}$ for $P e \mathrm{AAO} 2$ and $P e \mathrm{AAO} 1$ variants. After $N$-deglycosylation sharp bands at $70 \mathrm{kDa}$ appeared for all enzymes (lanes 2, 4, 6, and 8 in Fig. 2), indicating $30 \%$ of $\mathrm{N}$-glycosylation of recombinantly produced $P e A A O 1$ variants and $P e A A O 2$ wild-type.
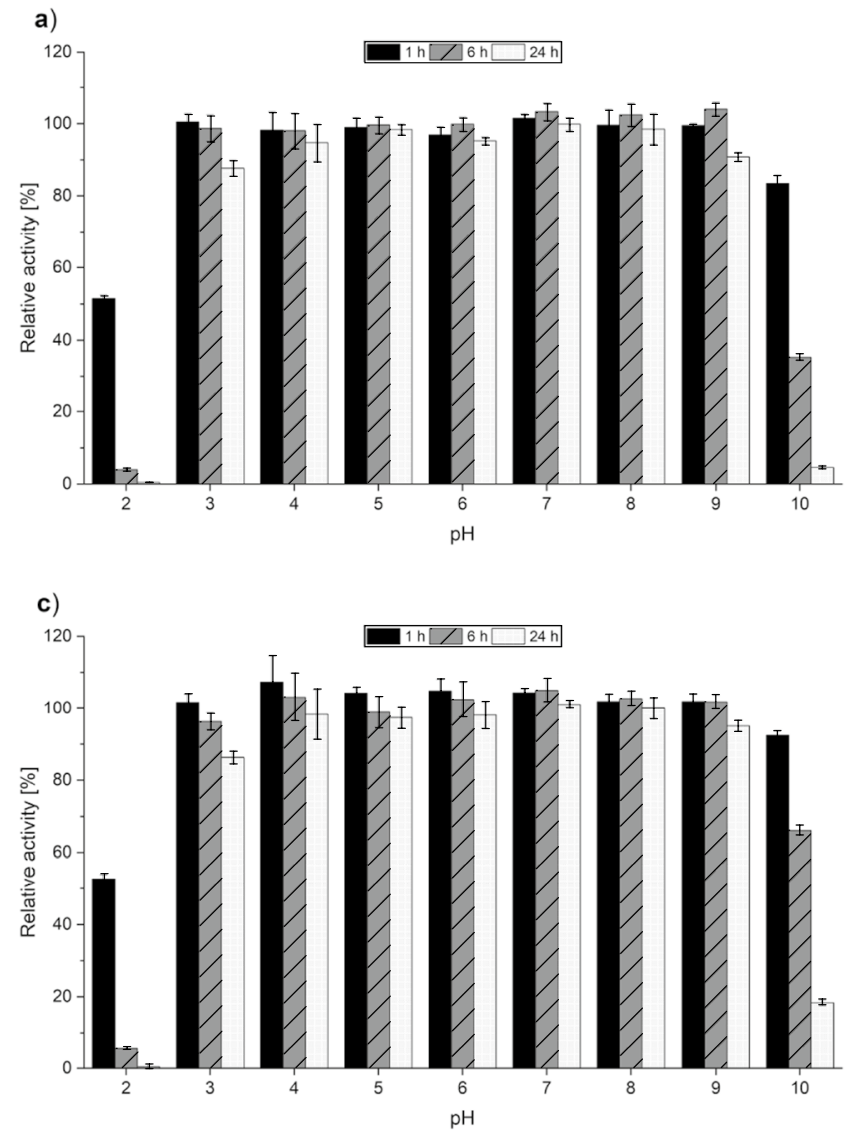

Fig. 3 pH stability profile of PeAAO1 variants a ER, b NER, c AER, and $\mathbf{d} P e \mathrm{AAO} 2$ wild-type after incubation in $100 \mathrm{mM}$ Britton-Robinson buffer $\mathrm{pH} 2$ to 10 for up to $24 \mathrm{~h}$. After $1 \mathrm{~h}$ : black, filled; after $6 \mathrm{~h}$ :

\section{pH activity and stability}

Regarding $\mathrm{pH}$ optimum, activity of PeAAO2 wild-type and PeAAO1 variants towards $p$-anisyl alcohol and veratryl alcohol was highest at slightly acidic $\mathrm{pH}$ values. The highest activity towards $p$-anisyl alcohol was at $\mathrm{pH} 5$ for PeAAO2 wild-type and PeAAO1 NER, while $\mathrm{pH} 6$ was best for PeAAO1 ER and AER (Supplemental Fig. S2a). $P e \mathrm{AAO} 2$ wild-type and all $P e \mathrm{AAO} 1$ variants showed the highest activity at $\mathrm{pH} 6$ with veratryl alcohol (Supplemental Fig. S2b).

Table 2 Melting temperature $\left(T_{\mathrm{M}}\right)$ and $\mathrm{T} T_{50}$ value of $P e A A O 1$ variants and $P e \mathrm{AAO} 2$ wild-type

\begin{tabular}{lllll}
\hline Enzyme & $P e$ AAO1 ER & $\begin{array}{l}\text { PeAAO1 } \\
\text { NER }\end{array}$ & $\begin{array}{l}\text { PeAAO1 } \\
\text { AER }\end{array}$ & $\begin{array}{l}\text { PeAAO2 } \\
\mathrm{WT}^{\mathrm{a}}\end{array}$ \\
\hline$T_{\mathrm{M}}\left[{ }^{\circ} \mathrm{C}\right]$ & 65.5 & 65.0 & 64.5 & 65.5 \\
$T_{50}\left[{ }^{\circ} \mathrm{C}\right]$ & 61.5 & 61.6 & 61.7 & 62.1 \\
\hline
\end{tabular}

${ }^{\mathrm{a}}$ Values from (Jankowski et al. 2020)
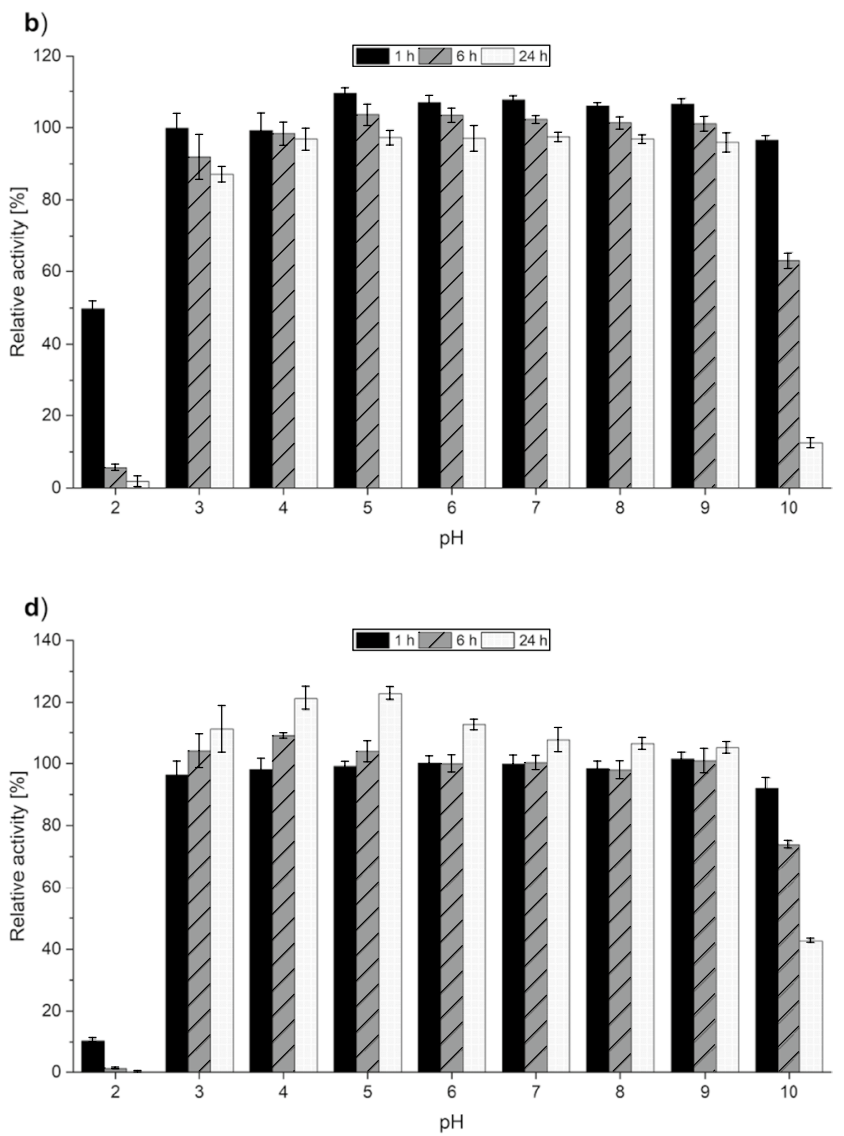

gray, striped; after $24 \mathrm{~h}$ : white, dotted. Initial activity without incubation was set to $100 \%$ 
High $\mathrm{pH}$ stability was found for all three $P e A A O 1$ variants ER, NER and AER with relative activities of over $85 \%$ after $24 \mathrm{~h}$ of incubation at $\mathrm{pH}$ ranging from 3 to 9 (Fig. 3a, b, and c). After $24 \mathrm{~h}$ incubation at $\mathrm{pH} 10$, activities dropped, and completely vanished after incubation at $\mathrm{pH} 2$ 2. PeAAO2 wild-type showed up to $130 \%$ increased relative activities after $24 \mathrm{~h}$ incubation between $\mathrm{pH} 3$ and 6 (Fig. 3d). Incubation at $\mathrm{pH} 2$ for $1 \mathrm{~h}$ seemed to have a more adverse effect on PeAAO2 wild-type as on the PeAAO1 variants, while $P e \mathrm{AAO} 2$ wild-type remained more active after incubation at $\mathrm{pH} 10$ with $40 \%$ relative activity as compared to the $P e \mathrm{AAO} 1$ variants.

\section{Thermal stability}

The melting temperature $T_{\mathrm{M}}$ was determined by measuring the FAD fluorescence during unfolding of the proteins at increasing temperatures. The $T_{\mathrm{M}}$ values for all $P e \mathrm{AAO} 1$ variants as well as for $\mathrm{PeAAO} 2$ wild-type were at around $65^{\circ} \mathrm{C}$ (Table 2), while the $T_{50}$ value at which half of the enzymatic activity lost after $10 \mathrm{~min}$ incubation was roughly 3 to $4{ }^{\circ} \mathrm{C}$ lower for all enzymes at around $61.5^{\circ} \mathrm{C}$.

\section{Specific activities and kinetic parameters}

Next, the specific activity of PeAAO1 variants towards p-anisyl alcohol, benzyl alcohol, trans,trans-2,4-hexadienol, piperonyl alcohol, and veratryl alcohol was determined. In general, specific activities of the PeAAO1 variants and $P e A A O 2$ wild-type were in the same range when using the same substrate (Supplemental Fig. S3). The highest specific activity was reached with trans,trans-2,4-hexadienol of up to

Table 3 Kinetic parameters of PeAAO1 variants and PeAAO2 wildtype towards the substrates $p$-anisyl alcohol and veratryl alcohol in $100 \mathrm{mM}$ sodium phosphate buffer $\mathrm{pH} 6$ at $25^{\circ} \mathrm{C}$

\begin{tabular}{cllll}
\hline Substrate & Enzyme & $\mathrm{K}_{\mathrm{M}}[\mu \mathrm{M}]$ & $\mathrm{k}_{\mathrm{cat}}\left[\mathrm{s}^{-1}\right]$ & $\begin{array}{l}\mathrm{k}_{\mathrm{cat}} / \mathrm{K}_{\mathrm{M}} \\
{\left[\mathrm{mM}^{-1} \mathrm{~s}^{-1}\right]}\end{array}$ \\
\hline $\begin{array}{c}p \text {-Anisyl } \\
\text { alcohol }\end{array}$ & PeAAO1 ER & $39.2 \pm 1.9$ & $73.8 \pm 0.03$ & 1883 \\
& PeAAO1 & $44.5 \pm 1.5$ & $87.9 \pm 0.06$ & 1975 \\
& NER & & & \\
& PeAAO1 & $48.8 \pm 1.5$ & $78.2 \pm 0.05$ & 1602 \\
& AER & & & \\
& PeAAO2 & 24.3 & 59.2 & 2436 \\
Veratryl & We ${ }^{\text {a }}$ & & & \\
alcohol & PeAAO1 ER & $549.0 \pm 12.6$ & $54.9 \pm 0.02$ & 100.0 \\
& NER & $546.7 \pm 5.8$ & $68.2 \pm 0.05$ & 124.7 \\
& PeAAO1 & $541.9 \pm 6.4$ & $58.5 \pm 0.03$ & 108.0 \\
& AER & & & \\
& PeAAO2 & 446.6 & 47.2 & 105.7 \\
& WT ${ }^{\text {a }}$ & & & \\
\hline
\end{tabular}

${ }^{a}$ Values from (Jankowski et al. 2020)
$89 \mathrm{U} / \mathrm{mg}$ for AER, followed by $p$-anisyl alcohol with up to $67 \mathrm{U} / \mathrm{mg}$ (NER). The lowest specific activities of $13 \mathrm{U} / \mathrm{mg}$ or below were observed during the oxidation of benzyl alcohol.

Kinetic measurements for the oxidation of $p$-anisyl alcohol and veratryl alcohol catalyzed by $P e A A O 1$ variants were conducted at $\mathrm{pH} 6$. The PeAAO1 variant NER showed the highest $\mathrm{k}_{\text {cat }}$ values with $87.9 \mathrm{~s}^{-1}$ and $68.2 \mathrm{~s}^{-1}$ for $p$-anisyl alcohol and veratryl alcohol, respectively, and also reached the highest catalytic efficiencies with $1975 \mathrm{mM}^{-1} \mathrm{~s}^{-1}$ and $124.7 \mathrm{mM}^{-1} \mathrm{~s}^{-1}$, respectively, among the three PeAAO1 variants (Table 3). The $\mathrm{K}_{\mathrm{M}}$ values for $p$-anisyl alcohol for the PeAAO1 variants were in the range from $39.2 \mu \mathrm{M}$ for ER to $48.8 \mu \mathrm{M}$ for AER. The $\mathrm{K}_{\mathrm{M}}$ values for veratryl alcohol were roughly 10 times higher than for $p$-anisyl alcohol and ranged from $541.9 \mu \mathrm{M}$ for AER to $549.0 \mu \mathrm{M}$ for ER. PeAAO2 wild-type showed the lowest $\mathrm{K}_{\mathrm{M}}$ values with $24.3 \mu \mathrm{M}$ and $446.6 \mu \mathrm{M}$ for $p$-anisyl alcohol and veratryl alcohol, respectively, and in case of $p$-anisyl alcohol also the highest overall catalytic efficiency with $2436 \mathrm{mM}^{-1} \mathrm{~s}^{-1}$.

\section{Gene copy number and mRNA levels}

Gene copy number and mRNA level of the target peaao genes of the most active $P$. pastoris transformant each expressing $P e \mathrm{AAO} 1$ wild-type, $P e \mathrm{AAO} 1$ variants $\mathrm{K} 583 \mathrm{E}$, Q584R, K583E/Q584R (ER), D361N/K583E (NE), V367A/ K583E (AE), NER, AER, and PeAAO2 wild-type, respectively, were determined (Fig. 4). The number of integrated genes varied between one for PeAAO1 wild-type and roughly 14 for PeAAO2 wild-type. The mRNA level increased with increasing gene copy number. However, although the volumetric activity was highest for PeAAO1 variants NER and AER with 56 and 52 U/l, respectively, the detected gene copy numbers and mRNA levels were roughly between one and two and thus among the lowest detected values. Interestingly, the $P$. pastoris transformant expressing PeAAO1 variant ER contained roughly 13 gene copies but showed a similar volumetric activity of $45 \mathrm{U} / 1$ as NER and AER with one to two gene copies and 3-4 times lower mRNA levels.

\section{Discussion}

The sequence of $P e \mathrm{AAO} 2$ was mimicked by mutating $P e A A O 1$ in a successive manner. Out of seven single $P e A A O 1$ mutants, only the mutation K583E led to measurable activity towards veratryl alcohol after expression in $P$. pastoris. By combining the mutations K583E and Q584R, volumetric activity increased from 3.7 to $131 \mathrm{U} / 1$, even though no functional expression was achieved for the single mutant Q584R. Here, we observe a synergistic positive effect of these two mutations on heterologous expression. 
Fig. 4 Relative gene copy number and mRNA level determination in correlation to volumetric activity [U/l] of $P e \mathrm{AAO} 1$ variants and $P e \mathrm{AAO} 2$ wild-type. Actin was used as reference gene and values are depicted as ratio of target gene and reference gene. Volumetric activity after $48 \mathrm{~h}$ expression in BMM medium $\left(25^{\circ} \mathrm{C}\right.$, $200 \mathrm{rpm}$ ) was determined towards $5 \mathrm{mM}$ veratryl alcohol in $100 \mathrm{mM}$ sodium phosphate buffer $\mathrm{pH}$ 6. Relative gene copy number: gray column, filled; relative mRNA level: white column, striped; volumetric activity: black squares. ER: double mutant K583E/Q584R; NE: double mutant D361N/ K583E; AE: double mutant V367A/K583E; NER: triple mutant D361N/K583E/Q584R; AER: triple mutant V367A/ K583E/Q584R

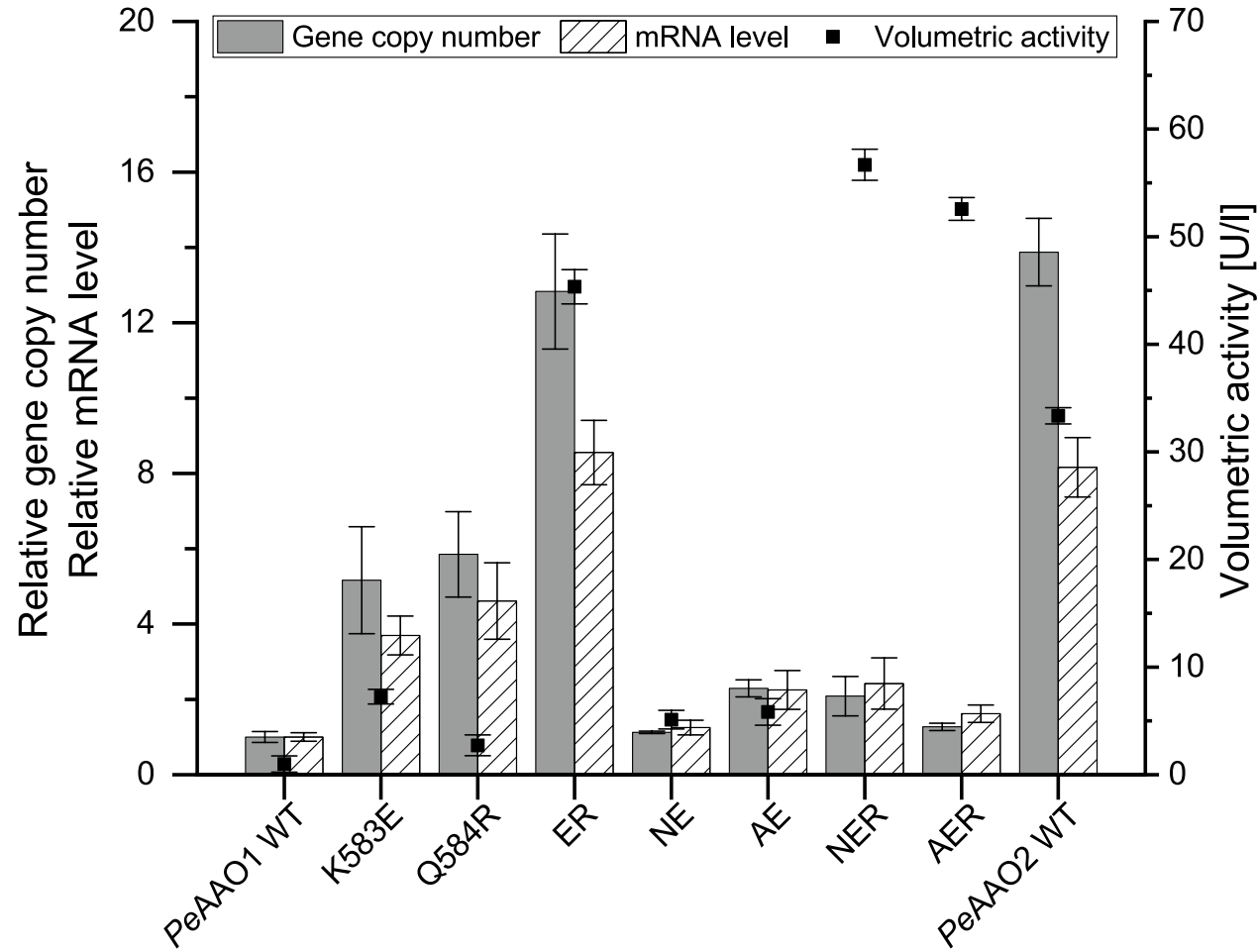

The introduction of either the mutation D361N or V367A further increased volumetric activities of the respective PeAAO1 variants NER and AER to 155 and $148 \mathrm{U} / 1$.

In an attempt to rationalize the positive effect of the four mutations on expression in P. pastoris, the PeAAO1 variants were investigated at different levels. First, homology models constructed for the PeAAO1 variants revealed that the neighboring mutations K583E and Q584R in the variant $\mathrm{ER}$ are located in the C-terminal $\alpha$-helix close to the surface of the enzyme (Fig. 5a). At position 583, the positively charged lysine in PeAAO1 wild-type (Lys583 in Fig. 5b) was replaced by the negatively charged glutamate (Glu583 in Fig. 5a), while at position 584, a polar glutamine (Gln584) was substituted with a positively charged arginine (Arg584). The introduction of Glu583 enables polar interactions with Arg47 and Lys153, both located less than $4 \AA$ away from Glu583 (Fig. 5c). Barlow and Thornton investigated the distance distribution of ion pairs in 38 structures of proteins and defined the distance of $\leq 4 \AA$ between two charged residues as criterion to form an ion pair (Barlow and Thornton 1983). It was shown that close-range electrostatic interactions between charged amino acid residues as in salt bridges contribute, among others, to protein folding and stability (Kumar and Nussinov 2002).

The positive charge of the guanidine moiety in Arg47 is delocalized among the three nitrogen atoms, which increases the probability to form ion pairs with suitable oppositely charged residues like Glu583 (Barlow and Thornton 1983). The $\varepsilon$-amino group of Lys 153 is also only $3.7 \AA$ away from
Glu583 and thus can also be involved in salt bridge formation. Musafia et al. performed an extended structure-based analysis of simple and complex salt bridges in 94 proteins and concluded that a central negatively charged glutamate residue can interact with an arginine via one or two bonds and additionally with a lysine via one bond, given that all charged groups are within the appropriate distance (Musafia et al. 1995). Thus, the mutation K583E might be involved in a new complex salt bridge formation with Arg47 and Lys 153 in the C-terminal $\alpha$-helix of the enzyme and might thereby influence the expression of PeAAO1 in $P$. pastoris by enhancing protein folding. PeAAO1 variant ER containing the additional mutation Q584R showed a dramatic enhancement of volumetric activity in comparison to K583E by factor 35, although the mutation Q584R alone did not lead to any observable expression. The homology model indicates that Arg584 is not in the ideal proximity to form salt bridges with other charged residues but might establish hydrogen bonds with main chain carbonyl groups of Asn 146 and/or Gly141 with distances between 2.4 and $3.8 \AA$, respectively (Fig. 5a). It has been proposed that arginine is able to participate in several hydrogen bonds with main chain carbonyl oxygens and thereby connect different structural elements, enhancing protein stability as well (Borders et al. 1994). Apparently both mutations K583E and Q584R have a synergistic effect on expression, probably due to improved folding or protein stability during processing which might positively influence protein translocation, FAD incorporation, or protein glycosylation. Possibly, once 
Fig. 5 Location of mutations $\mathrm{K} 583 \mathrm{E} / \mathrm{Q} 584 \mathrm{R}$ in a $\mathrm{PeAAO} 1$ variant ER and $\mathbf{b}$ the same positions in wild-type $\mathrm{PeAAO} 1$; c close-up on possible polar contacts of variant ER; $\mathbf{d}$ mutation D361N in PeAAO1 NER and e mutation V367A in PeAAO1 AER. The two introduced mutations leading to Glu583 and Arg584 are depicted in pink; amino acid residues and backbone atoms in close proximity to form polar contacts (Arg47, Lys153, Asn146, Gly141, Asp139) are depicted in gray (a). View of the same positions in wild-type $P e \mathrm{AAO} 1$ with Lys583 and Gln584 depicted in yellow (b). Close-up on possible polar contacts in variant ER at position 583 (c). The introduced mutations D361N and V367A in variants NER and AER are depicted in pink (d and e). The homology models of $P e$ AAO1 variants ER, NER, and AER were created using the crystal structure of $P$. eryngii AAO (wild-type $P e$ AAO1) (PDB entry 3FIM) as template. The possible polar contacts are colored in green and predicted distances are given in $\AA$
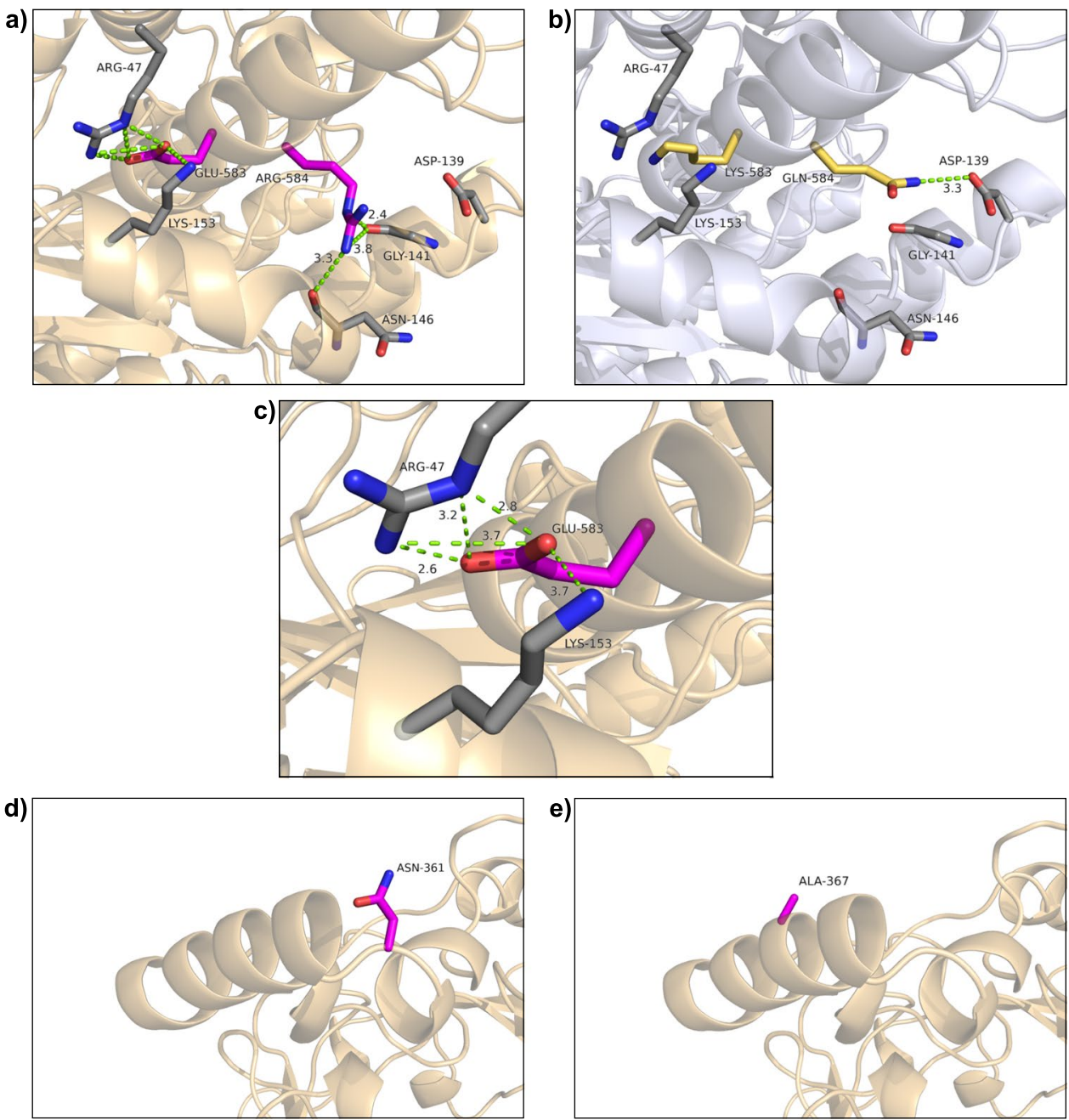

the mutation Q584R is introduced to generate variant ER, the protein folding is slightly altered and the proposed salt bridges of Glu583 can be formed which eventually leads to the increased expression of this enzyme variant. It is important to point out that all assumptions are based on homology models built on the basis of the crystal structure of the non-glycosylated holoprotein PeAAO1, crystallized after expression and refolding from inclusion bodies in $E$. coli (Fernández et al. 2009). Glycan moieties present in the three $\mathrm{PeAAO1}$ variants might influence folding of the enzymes so that crystal structures might differ from the predicted ones. Moreover, the mutations introduced in PeAAO1 could have an impact on FAD binding as the position Arg47 involved in the hypothesized salt bridge is located in an N-terminal helix closely located to the highly conserved dinucleotide-binding motif (Fernández et al. 2009). Crystal structures of the glycosylated $P e \mathrm{AAO} 2$ and the $P e \mathrm{AAO} 1$ variants expressed in $P$. pastoris could provide more insight into possible structural changes induced by the introduced mutations. However, due to the heterogeneity caused by attached glycan moieties, crystallization of glycoproteins is a challenging task
(Chang et al. 2007) and up to now has only been described for one glycosylated AAO - MtAAOx from Thermothelomyces thermophilus (Kadowaki et al. 2020).

The additionally introduced mutations D361N or V367A are located in a surface exposed $\alpha$-helix on the enzyme surface (Fig. $5 \mathrm{~d}$ and e), which is unique for AAOs in comparison to other family members of the glucose-methanolcholine (GMC) oxidoreductase superfamily (Fernández et al. 2009). While no direct conclusion for the effect of the mutation V367A can be drawn based on structure-related changes, the mutation $\mathrm{D} 361 \mathrm{~N}$ introduces a new potential $\mathrm{N}$-glycosylation site with the general motif of Asn-X-Ser/ $\mathrm{Thr}$, where $\mathrm{X}$ is any amino acid except for proline (Kukuruzinska et al. 1987). Glycosylation may assist various processes like protein folding (Helenius and Aebi 2004), stabilization of mature protein structures (Imperiali and O'Connor 1999; Wormald and Dwek 1999; Wyss and Wagner 1996), and thermostability of the protein (Wang et al. 1996). With the newly introduced $\mathrm{N}$-glycosylation site, $\mathrm{PeAAO} 1$ variant NER contains a total of eight potential sites which are identical to PeAAO2 wild-type (Jankowski et al. 2020). All three 
$P e A A O 1$ variants and $P e A A O 2$ wild-type exhibit highly similar molecular weights and $\mathrm{N}$-glycosylation contents according to SDS-PAGE and PNGase F treatment as well as similar high $\mathrm{pH}$ and thermostability. The high $\mathrm{pH}$ stability of all variants is comparable to that observed for PeAAO1 variant FX7 expressed in S. cerevisiae, which contained 50\% glycosylation content (Viña-Gonzalez et al. 2015). It should be noted that most likely not all predicted $\mathrm{N}$-glycosylation sites are in fact glycosylated. A database-survey focused on glycoproteins revealed that on average only two thirds of $\mathrm{N}$-glycosylation sites are occupied (Apweiler et al. 1999). For example, the MtAAOx from T. thermophilus contains six predicted $\mathrm{N}$-glycosylation sites and X-ray structure elucidation revealed that four of them were glycosylated while one of them presents the major $\mathrm{N}$-glycosylation site (Kadowaki et al. 2020). Interestingly, the previously reported optimized FX9 variant of PeAAO1 expressed in P. pastoris was poorly glycosylated despite the presence of seven predicted $N$-glycosylation sites (Viña-Gonzalez et al. 2018), identical to the ones present in PeAAO1 ER and AER. Maybe Asn361 in NER is only slightly $N$-glycosylated and therefore only marginal differences in glycan pattern of NER and the other variants exist that are not detectable via SDSPAGE. In this case, the additional $N$-glycosylation in variant NER (and NE) could positively affect protein folding and/ or secretion of the enzyme leading to enhanced volumetric activities. Stabilities of the purified PeAAO1 variants and $\mathrm{PeAAO} 2$ wild-type were comparable and showed no major differences: all $P e A A O 1$ variants exhibited high $\mathrm{pH}$ stabilities with roughly $90 \%$ of activity after incubation at $\mathrm{pH} 3$ to 9 for $24 \mathrm{~h}, T_{\mathrm{M}}$ values at around $65^{\circ} \mathrm{C}$, and $T_{50}$ values between 61.5 and $62{ }^{\circ} \mathrm{C}$.

The gene copy numbers and mRNA levels varied among the recombinant $P$. pastoris strains. Most strikingly, strains expressing the variants AER and NER demonstrated only one to two gene copies and similar high mRNA levels while exhibiting the highest observed volumetric activities. By comparing these data with the strain expressing the double mutant ER, which contained roughly 13 copies and showed a slightly lower volumetric activity than the triple mutants, our results indicate that the same (or even higher) level of volumetric AAO activity can be achieved with the triple mutants likely due to lower metabolic burden with just one to two gene copies. Overall, the real-time PCR results indicate that the observed higher volumetric activity of variants NER and AER can be solely attributed to effects of the mutations rather than multiple integration of the aao genes.

Since volumetric activity is dependent on enzyme concentration, on the one hand, and on catalytic properties of this enzyme, on the other hand, it is important to compare the catalytic parameters of the mutants. In general, catalytic activity of all $P e A A O 1$ variants was higher compared to PeAAO2 wild-type. Thereby, mutations D361N and V367A seem to have a stimulating effect on catalytic activity when combined with ER mutations. The specific activities of the $P e A A O 1$ variants NER and AER measured for several substrates were slightly higher than those of PeAAO1 ER and even $P e \mathrm{AAO} 2$ wild-type. The $\alpha$-helix which harbors both positions is the most external structural element in proximity to the catalytic pocket and might therefore influence substrate access to the active site. Interestingly, PeAAO2 wild-type showed lowest $\mathrm{K}_{\mathrm{M}}$ values for $p$-anisyl alcohol and veratryl alcohol (Jankowski et al. 2020). PeAAO1 variant NER showed the highest $\mathrm{k}_{\mathrm{cat}}$ value among all PeAAO1 variants and $P e \mathrm{AAO} 2$ wild-type, followed by variant AER, which could explain, at least to some extent, their increased volumetric activities after expression compared to PeAAO2.

Comparison of catalytic properties of the PeAAO1 variants with other AAOs showed that catalytic efficiencies of the PeAAO1 variants are in the same range as compared to the poorly glycosylated PeAAO1 variant FX9 expressed in $P$. pastoris with efficiencies of $1909 \mathrm{mM}^{-1} \mathrm{~s}^{-1}$ ( $p$-anisyl alcohol) and $139 \mathrm{mM}^{-1} \mathrm{~s}^{-1}$ (veratryl alcohol) (ViñaGonzalez et al. 2018). Interestingly, PeAAO1 wild-type expressed in A. nidulans showed higher catalytic efficiencies with $5233 \mathrm{mM}^{-1} \mathrm{~s}^{-1}$ (p-anisyl alcohol) and $210 \mathrm{mM}^{-1} \mathrm{~s}^{-1}$ (veratryl alcohol) and up to two times higher $\mathrm{k}_{\text {cat }}$ values with $142 \mathrm{~s}^{-1}$ and $114 \mathrm{~s}^{-1}$ for $p$-anisyl alcohol and veratryl alcohol, respectively (Ferreira et al. 2006). While UmAAO from Ustilago maydis expressed in P. pastoris exhibited higher catalytic efficiencies towards $p$-anisyl alcohol $\left(9380 \mathrm{mM}^{-1} \mathrm{~s}^{-1}\right)$ and veratryl alcohol $\left(440 \mathrm{mM}^{-1} \mathrm{~s}^{-1}\right)(\mathrm{Cou}-$ turier et al. 2016), than the PeAAO1 variants, $\mathrm{rCc}$ AAO from Coprinopsis cinerea expressed in P. pastoris showed a lower catalytic efficiency for conversion of $p$-anisyl alcohol with $1077 \mathrm{mM}^{-1} \mathrm{~s}^{-1}$ (Tamaru et al. 2018). On the other hand, $\mathrm{r} C \mathrm{AAO}$ showed an up to two times higher catalytic efficiency towards veratryl alcohol and a higher substrate affinity with $\mathrm{K}_{\mathrm{M}}$ of $48.3 \mu \mathrm{M}$ as compared to 446 to $549 \mu \mathrm{M}$ for the PeAAO1 variants. MtAAOx from T. thermophilus showed quite low catalytic efficiencies with only $0.007 \mathrm{mM}^{-1} \mathrm{~s}^{-1}$ and $0.011 \mathrm{mM}^{-1} \mathrm{~s}^{-1}$ towards $p$-anisyl alcohol and veratryl alcohol, respectively (Kadowaki et al. 2020).

In conclusion, site-directed mutagenesis of $P$. eryngii $P e A A O 1$ led to the generation of three active and readily expressible enzyme variants with expression levels exceeding those of the already described PeAAO1 variants. Up to now, the highest expression reported for the FX9 variant of PeAAO1 in P. pastoris was $25.5 \mathrm{mg} / \mathrm{l}$ (Viña-Gonzalez et al. 2018). Here, PeAAO1 variants ER, NER, and AER were constructed and expressed at four to fivefold higher concentrations ranging between 98 and $116 \mathrm{mg} / \mathrm{l}$, accompanied by high volumetric activities. All enzymes could be produced in a bioreactor at 31 scale, purified, and characterized.

The synergistic stabilizing effect caused by the introduced mutations K583E and Q584R is hypothesized. The 
introduced mutations also slightly affected the catalytic properties of the enzyme variants. In future studies, the beneficial effect of mutations K583E/Q584R on PeAAO1 expression could be combined with the reported mutations affecting enzyme selectivity and activity, such as in the oxidation of secondary benzylic alcohols (Viña-Gonzalez et al. 2019). This way, enzyme variants with new or improved catalytic activities and enhanced expression yields could become easily accessible for large-scale biocatalytic applications.

Supplementary Information The online version contains supplementary material available at https://doi.org/10.1007/s00253-021-11585-4.

Acknowledgements We thank Vanessa Göttfert for contribution to production and purification of PeAAO1 variants, and collection of data for thermal stability experiments.

Author contribution $\mathrm{NJ}$ designed and conducted the experiments, analyzed the data, evaluated the results, and drafted the manuscript. KK and VBU gave advice in the research work, interpretation of data and helped in drafting and writing of the manuscript. All authors approved the manuscript.

Funding Open Access funding enabled and organized by Projekt DEAL. This work was financially supported by Bioeconomy Science Center supported by the Ministry of Innovation, Science and Research within the frame- work of the North Rhine-Westphalia, Germany, NRW-Strategieprojekt BioSC (Grant No. 313/323-400-002 13).

Data availability All data on which the conclusions were drawn are presented in this study.

Code availability Not applicable.

\section{Declarations}

Ethical approval This article does not contain any studies with human participants or animals performed by any of the authors.

Competing interests The authors declare no competing interests.

Open Access This article is licensed under a Creative Commons Attribution 4.0 International License, which permits use, sharing, adaptation, distribution and reproduction in any medium or format, as long as you give appropriate credit to the original author(s) and the source, provide a link to the Creative Commons licence, and indicate if changes were made. The images or other third party material in this article are included in the article's Creative Commons licence, unless indicated otherwise in a credit line to the material. If material is not included in the article's Creative Commons licence and your intended use is not permitted by statutory regulation or exceeds the permitted use, you will need to obtain permission directly from the copyright holder. To view a copy of this licence, visit http://creativecommons.org/licenses/by/4.0/.

\section{References}

Apweiler R, Hermjakob H, Sharon N (1999) On the frequency of protein glycosylation, as deduced from analysis of the SWISS-PROT database. Biochim Biophys Acta 1473(1):4-8. https://doi.org/10. 1097/00013611-198607000-00004

Barlow DJ, Thornton JM (1983) Ion-pairs in proteins. J Mol Biol 168(4):867-885. https://doi.org/10.1016/s0022-2836(83)80079-5

Borders CL, Broadwater JA, Bekeny PA, Salmon JE, Lee AS, Eldridge AM, Pett VB (1994) A structural role for arginine in proteins: multiple hydrogen bonds to backbone carbonyl oxygens. Protein Sci 3(4):541-548. https://doi.org/10.1002/pro.5560030402

Bradford MM (1976) A rapid and sensitive method for the quantitation of microgram quantities of protein utilizing the principle of protein-dye binding. Anal Biochem 72:248-254. https://doi.org/ 10.1016/0003-2697(76)90527-3

Carro J, Ferreira P, Martínez ÁT, Gadda G (2018) Stepwise hydrogen atom and proton transfers in dioxygen reduction by aryl-alcohol oxidase. Biochemistry 57(11):1790-1797. https://doi.org/10.1021/ acs.biochem. 8 b00106

Carro J, Ferreira P, Rodríguez L, Prieto A, Serrano A, Balcells B, Ardá A, Jiménez-Barbero J, Gutiérrez A, Ullrich R, Hofrichter M, Martínez ÁT (2014) 5-Hydroxymethylfurfural conversion by fungal aryl-alcohol oxidase and unspecific peroxygenase. FEBS J 282:3218-3229. https://doi.org/10.1111/febs.13177

Carro J, Martínez M, Medina M, Martínez ÁT, Ferreira P (2017) Protein dynamics promote hydride tunnelling in substrate oxidation by aryl-alcohol oxidase. Phys Chem Chem Phys 19:28666-28675. https://doi.org/10.1039/C7CP05904C

Chang VT, Crispin M, Aricescu AR, Harvey DJ, Nettleship JE, Fennelly JA, Yu C, Boles KS, Evans EJ, Stuart DI, Dwek RA, Jones EY, Owens RJ, Davis SJ (2007) Glycoprotein structural genomics: solving the glycosylation problem. Structure 15(3):267-273. https://doi.org/10.1016/j.str.2007.01.011

Couturier M, Mathieu Y, Li A, Navarro D, Drula E, Haon M, Grisel S, Ludwig R, Berrin JG (2016) Characterization of a new arylalcohol oxidase secreted by the phytopathogenic fungus Ustilago maydis. Appl Microbiol Biotechnol 100(2):697-706. https://doi. org/10.1007/s00253-015-7021-3

de Almeida TP, van Schie MMCH, Ma A, Tieves F, Younes SHH, Fernández-Fueyo E, Arends IWCE, Riul A, Hollmann F (2019) Efficient aerobic oxidation of trans-2-hexen-1-ol using the aryl alcohol oxidase from Pleurotus eryngii. Adv Synth Catal 361:2668-2672. https://doi.org/10.1002/adsc.201801312

Dijkman WP, de Gonzalo G, Mattevi A, Fraaije MW (2013) Flavoprotein oxidases: classification and applications. Appl Microbiol Biotechnol 97:5177-5188. https://doi.org/10.1007/ s00253-013-4925-7

Fernández IS, Ruíz-Dueñas FJ, Santillana E, Ferreira P, Martínez MJ, Martínez ÁT, Romero A (2009) Novel structural features in the GMC family of oxidoreductases revealed by the crystal structure of fungal aryl-alcohol oxidase. Acta Crystallogr Sect D Biol Crystallogr 65:1196-1205. https://doi.org/10.1107/S090744490 9035860

Ferreira P, Hernández-Ortega A, Herguedas B, Martínez ÁT, Medina M (2009) Aryl-alcohol oxidase involved in lignin degradation. A mechanistic study based on steady and pre-steady state kinetics and primary and solvent isotope effects with two alcohol substrates. J Biol Chem 284:24840-24847. https://doi.org/10.1074/ jbc.M109.011593

Ferreira P, Hernández-Ortega A, Herguedas B, Rencoret J, Gutiérrez A, Martínez MJ, Jiménez-Barbero J, Medina M, Martínez ÁT (2010) Kinetic and chemical characterization of aldehyde oxidation by fungal aryl-alcohol oxidase. Biochem J 425:585-593. https://doi. org/10.1042/BJ20091499

Ferreira P, Medina M, Guillén F, Martínez MJ, van Berkel WJH, Martínez AT (2005) Spectral and catalytic properties of aryl-alcohol oxidase, a fungal flavoenzyme acting on polyunsaturated alcohols. Biochem J 389:731-738. https://doi.org/10.1042/BJ20041903 
Ferreira P, Ruiz-Dueñas FJ, Martínez MJ, Van Berkel WJH, Martínez AT (2006) Site-directed mutagenesis of selected residues at the active site of aryl-alcohol oxidase, an $\mathrm{H}_{2} \mathrm{O}_{2}$-producing ligninolytic enzyme. FEBS J 273:4878-4888. https://doi.org/10.1111/j.17424658.2006.05488.x

Forneris F, Orru R, Bonivento D, Chiarelli LR, Mattevi A (2009) ThermoFAD, a Thermofluor ${ }^{\circledR}$-adapted flavin ad hoc detection system for protein folding and ligand binding. FEBS J 276:2833-2840. https://doi.org/10.1111/j.1742-4658.2009.07006.x

Grote A, Hiller K, Scheer M, Münch R, Nörtemann B, Hempel DC, Jahn D (2005) JCat: A novel tool to adapt codon usage of a target gene to its potential expression host. Nucleic Acids Res 33:526531. https://doi.org/10.1093/nar/gki376

Guillén F, Martínez ÁT, Martínez MJ (1992) Substrate specificity and properties of the aryl-alcohol oxidase from the ligninolytic fungus Pleurotus eryngii. Eur J Biochem 209:603-611. https://doi.org/ 10.1111/j.1432-1033.1992.tb17326.x

Helenius A, Aebi M (2004) Roles of N-linked glycans in the endoplasmic reticulum. Annu Rev Biochem 73:1019-1049. https://doi.org/ 10.1146/annurev.biochem.73.011303.073752

Hernández-Ortega A, Ferreira P, Merino P, Medina M, Guallar V, Martínez ÁT (2012a) Stereoselective hydride transfer by aryl-alcohol oxidase, a member of the GMC superfamily. ChemBioChem 13:427-435. https://doi.org/10.1002/cbic.201100709

Hernández-Ortega A, Lucas F, Ferreira P, Medina M, Guallar V, Martínez ÁT (2012b) Role of active site histidines in the two halfreactions of the aryl-alcohol oxidase catalytic cycle. Biochemistry 51:6595-6608. https://doi.org/10.1021/bi300505z

Imperiali B, O'Connor SE (1999) Effect of N-linked glycosylatian on glycopeptide and glycoprotein structure. Curr Opin Chem Biol 3(6):643-649. https://doi.org/10.1016/S1367-5931(99)00021-6

Jankowski N, Koschorreck K, Urlacher VB (2020) High-level expression of aryl-alcohol oxidase 2 from Pleurotus eryngii in Pichia pastoris for production of fragrances and bioactive precursors. Appl Microbiol Biotechnol 104(21):9205-9218. https://doi.org/ 10.1007/s00253-020-10878-4

Kadowaki MAS, Higasi PMR, de Godoy MO, de Araujo EA, Godoy AS, Prade RA, Polikarpov I (2020) Enzymatic versatility and thermostability of a new aryl-alcohol oxidase from Thermothelomyces thermophilus M77. Biochim Biophys Acta 10:129681. https://doi. org/10.1016/j.bbagen.2020.129681

Kukuruzinska MA, Bergh MLE, Jackson BJ (1987) Protein glycosylation in yeast. Annu Rev Biochem 56:915-944. https://doi.org/10. 1146/annurev.bi.56.070187.004411

Kumar S, Nussinov R (2002) Close-range electrostatic interactions in proteins. ChemBioChem 3(7):604-617. https://doi.org/10.1002/ 1439-7633(20020703)3:7\%3c604::AID-CBIC604\%3e3.0.CO;2-X

Laemmli UK (1970) Cleavage of structural proteins during assembly of head of bacteriophage-T4. Nature 227:680-685. https://doi.org/ $10.1038 / 227680 \mathrm{a} 0$

Li Y, Cirino PC (2014) Recent advances in engineering proteins for biocatalysis. Biotechnol Bioeng 111(7):1273-1287. https://doi. org/10.1002/bit.25240

Musafia B, Buchner V, Arad D (1995) Complex salt bridges in proteins: statistical analysis of structure and function. J Mol Biol 254(4):761-770. https://doi.org/10.1006/jmbi.1995.0653

Pfaffl MW (2001) A new mathematical model for relative quantification in real-time RT-PCR. Nucleic Acids Res 29(9):e45. https://doi. org/10.1111/j.1365-2966.2012.21196.x

Ruiz-Dueñas FJ, Ferreira P, Martínez MJ, Martínez AT (2006) In vitro activation, purification, and characterization of Escherichia coli expressed aryl-alcohol oxidase, a unique $\mathrm{H}_{2} \mathrm{O}_{2}$-producing enzyme. Protein Expression Purif 45(1):191-199. https://doi.org/10.1016/j. pep.2005.06.003
Serrano A, Calviño E, Carro J, Sánchez-Ruiz MI, Cañada FJ, Martínez AT (2019a) Complete oxidation of hydroxymethylfurfural to furandicarboxylic acid by aryl-alcohol oxidase. Biotechnol Biofuels 12:217. https://doi.org/10.1186/s13068-019-1555-z

Serrano A, Carro J, Martínez ÁT (2020) Reaction mechanisms and applications of aryl-alcohol oxidase. In: Chaiyen P, Tamanoi F (eds) The Enzymes. Flavin-Dependent Enzymes: Mechanisms, Structures and Applications, Vol 47, 2020 edn. Elsevier, pp 167-192

Serrano A, Sancho F, Viña-González J, Carro J, Alcalde M, Guallar V, Martínez ÁT (2019b) Switching the substrate preference of fungal aryl-alcohol oxidase: towards stereoselective oxidation of secondary benzyl alcohols. Catal Sci Technol 9:833-841. https:// doi.org/10.1039/C8CY02447B

Tamaru Y, Umezawa K, Yoshida M (2018) Characterization of an aryl-alcohol oxidase from the plant saprophytic basidiomycete Coprinopsis cinerea with broad substrate specificity against aromatic alcohols. Biotechnol Lett 40(7):1077-1086. https://doi.org/ 10.1007/s10529-018-2534-3

Urlacher VB, Koschorreck K (2021) Pecularities and applications of aryl-alcohol oxidases from fungi. Appl Microbiol Biotechnol 105:4111-4126. https://doi.org/10.1007/s00253-021-11337-4

van Schie MMCH, de Almeida TP, Laudadio G, Tieves F, FernándezFueyo E, Noël T, Arends IWCE, Hollmann F (2018) Biocatalytic synthesis of the green note trans-2-hexenal in a continuous-flow microreactor. Beilstein J Org Chem 14:697-703. https://doi.org/ 10.3762/bjoc. 14.58

Viña-Gonzalez J, Alcalde M (2020) Directed evolution of the arylalcohol oxidase: beyond the lab bench. Comput Struct Biotechnol J 18:1800-1810. https://doi.org/10.1016/j.csbj.2020.06.037

Viña-Gonzalez J, Elbl K, Ponte X, Valero F, Alcalde M (2018) Functional expression of aryl-alcohol oxidase in Saccharomyces cerevisiae and Pichia pastoris by directed evolution. Biotechnol Bioeng 115(7):1666-1674. https://doi.org/10.1002/bit.26585

Viña-Gonzalez J, Gonzalez-Perez D, Ferreira P, Martínez ÁT, Alcalde M (2015) Focused directed evolution of aryl-alcohol oxidase in Saccharomyces cerevisiae by using chimeric signal peptides. Appl Environ Microbiol 81(18):6451-6462. https://doi.org/10.1128/ AEM.01966-15

Viña-Gonzalez J, Jimenez-Lalana D, Sancho F, Serrano A, Martínez ÁT, Guallar V, Alcalde M (2019) Structure-guided evolution of aryl alcohol oxidase from Pleurotus eryngii for the selective oxidation of secondary benzyl alcohols. Adv Synth Catal 361:2514 2525. https://doi.org/10.1002/adsc.201900134

Wang C, Eufemi M, Turano C, Giartosio A (1996) Influence of the carbohydrate moiety on the stability of glycoproteins. Biochemistry 35(23):7299-7307. https://doi.org/10.1021/bi9517704

Waterhouse A, Bertoni M, Bienert S, Studer G, Tauriello G, Gumienny R, Heer FT, de Beer TAP, Rempfer C, Bordoli L, Lepore R, Schwede T (2018) SWISS-MODEL: homology modelling of protein structures and complexes. Nucleic Acids Res 46(W1):W296W303. https://doi.org/10.1093/nar/gky427

Wormald MR, Dwek RA (1999) Glycoproteins: glycan presentation and protein-fold stability. Structure 7(7):155-160. https://doi.org/ 10.1016/S0969-2126(99)80095-1

Wyss DF, Wagner G (1996) The structural role of sugars in glycoproteins. Curr Opin Biotechnol 7(4):409-416. https://doi.org/10. 1016/S0958-1669(96)80116-9

Publisher's note Springer Nature remains neutral with regard to jurisdictional claims in published maps and institutional affiliations. 